\title{
The Inactivation by Curcumin-Mediated Photosensitization of Botrytis cinerea Spores Isolated from Strawberry Fruits
}

\author{
Li Huang ${ }^{1}$, Ken W. L. Yong ${ }^{2}{ }^{\oplus}$, W. Chrishanthi Fernando ${ }^{3}$, Matheus Carpinelli de Jesus ${ }^{4}{ }^{\oplus}$, James J. De Voss ${ }^{4}{ }^{\circledR}$, \\ Yasmina Sultanbawa ${ }^{3, *(\mathbb{D})}$ and Mary T. Fletcher ${ }^{3, *(\mathbb{D}}$ \\ 1 Institute of Light Industry and Food Engineering, Guangxi University, Nanning 530004, China; \\ mary607@126.com \\ 2 Queensland Department of Agriculture and Fisheries, 39 Kessels Rd, Coopers Plains, QLD 4108, Australia; \\ ken.yong@daf.qld.gov.au \\ 3 Queensland Alliance for Agriculture and Food Innovation (QAAFI), The University of Queensland, \\ 39 Kessels Rd, Coopers Plains, QLD 4108, Australia; chrishanthif2@gmail.com \\ 4 School of Chemistry and Molecular Biosciences, The University of Queensland, St Lucia, QLD 4072, Australia; \\ m.carpinellidejesus@uq.edu.au (M.C.d.J.); j.devoss@uq.edu.au (J.J.D.V.) \\ * Correspondence: y.sultanbawa@uq.edu.au (Y.S.); Mary.fletcher@uq.edu.au (M.T.F.)
}

check for updates

Citation: Huang, L.; Yong, K.W.L.; Fernando, W.C.; Carpinelli de Jesus, M.; De Voss, J.J.; Sultanbawa, Y.; Fletcher, M.T. The Inactivation by Curcumin-Mediated

Photosensitization of Botrytis cinerea Spores Isolated from Strawberry Fruits. Toxins 2021, 13, 196. https:// doi.org/10.3390/toxins13030196

Received: 5 February 2021

Accepted: 4 March 2021

Published: 9 March 2021

Publisher's Note: MDPI stays neutral with regard to jurisdictional claims in published maps and institutional affiliations.

Copyright: (c) 2021 by the authors. Licensee MDPI, Basel, Switzerland. This article is an open access article distributed under the terms and conditions of the Creative Commons Attribution (CC BY) license (https:// creativecommons.org/licenses/by/ $4.0 /)$.

\begin{abstract}
Photosensitization is a novel environmentally friendly technology with promising applications in the food industry to extend food shelf life. In this study, the natural food dye curcumin, when combined with visible light $(430 \mathrm{~nm})$, was shown to be an effective photosensitizer against the common phytopathogenic fungi Botrytis cinerea (the cause of grey mould). Production of the associated phytotoxic metabolites botrydial and dihydrobotrydial was measured by our newly developed and validated HRAM UPLC-MS/MS method, and was also shown to be reduced by this treatment. With a light dose of $120 \mathrm{~J} / \mathrm{cm}^{2}$, the reduction in spore viability was directly proportional to curcumin concentrations, and the overall concentration of both botrydial and dihydrobotrydial also decreased with increasing curcumin concentration above $200 \mu \mathrm{M}$. With curcumin concentrations above $600 \mu \mathrm{M}$, the percentage reduction in fungal spores was close to $100 \%$. When the dye concentration was increased to $800 \mu \mathrm{M}$, the spores were completely inactive and neither botrydial nor dihydrobotrydial could be detected. These results suggest that curcumin-mediated photosensitization is a potentially effective method to control B. cinerea spoilage, and also to reduce the formation of these phytotoxic botryane secondary metabolites.
\end{abstract}

Keywords: photodynamic therapy; botryane; secondary metabolites; dihydrobotrydial; fungal spoilage

Key Contribution: Curcumin-mediated photosensitization is effective in the control of Botrytis cinerea and reduces the formation of phytotoxic botrydial and dihydrobotrydial as measured by a newly developed and validated HRAM UPLC-MS/MS method. Photosensitization is a promising eco-friendly treatment to control food spoilage in strawberries.

\section{Introduction}

Strawberries are one of the most popular fruits consumed worldwide, with global production in excess of $9 \mathrm{M}$ tons per annum and an estimated annual production value of USD 18B worldwide [1]. These fruits are rich sources of antioxidants and vitamin C [2], but their commercial value is restricted by limited shelf-life due largely to susceptibility to microbial infections, particularly Botrytis grey mould. Botrytis cinerea is the causal agent of this disease, which effects not only strawberries, and is considered one of the most important phytopathogens of horticultural crops. This fungus is found in more than 200 ornamental and agriculturally important plants in the world, and ranks second in the list of 'top 10' fungal plant pathogens [3].

Antimicrobial photosensitization is an effective and promising approach to elicit cell death and kill microorganisms such as Gram-negative and Gram-positive bacteria and 
yeasts, as well as parasites and viruses [4-6]. The basic principle of photosensitization is a photochemical process in which a photosensitizer dye such as crystal violet, methylene blue and safranin $\mathrm{O}$ are energized to an unstable singlet excited-state after absorbing light photons, and then loses its excess energy to produce free radicals including superoxide and hydroxyl radicals (Type I pathway) and singlet oxygen (Type II pathway). These reactive oxygen species (ROS) cause oxidative damage to biomolecules including amino acids, lipids, nucleic acids, with ensuing cell death $[7,8]$. The application of natural plant additives such as curcumin as photosensitizer is considered a clean and green technology with minimal reported adverse impacts [9]. By comparison fungicides, and other methods, such as irradiation, biocontrol agents, etc., that are currently used to extend food shelf life, show unfavourable side effects that can impact on consumer health. Photosensitization is thus being investigated as a novel technology to accomplish microbiological decontamination and extend the shelf life of food in an environmentally friendly way.

B. cinerea has many unique characteristics in its phytopathological behaviour, including the capacity to kill host cells through both the production of toxins and also oxidative burst (reactive oxygen species) generated by both the host and the pathogen [10]. This fungus is both a pathogenic and saprophytic organism, initially infecting the weak or dead parts of the plant, and then extending to the rest of healthy plant tissue [11]. $B$. cinerea produces characteristic fungal metabolites based on the botryane skeleton, principally botrydial (1) and its metabolite dihydrobotrydial (2) (Figure 1), which have been isolated from fungal culture medium [12]. Botrydial is a particularly powerful phytotoxin, produced during plant infection, which can induce chlorosis and cell collapse. It has been demonstrated to have phytotoxic and cytotoxic activity at $\mathrm{ID}_{50}$ as equal to or lower than $5 \mu \mathrm{g} / \mathrm{mL}$ and antibiotic activity at $100 \mathrm{ppm}$ [13]. A further B. cinerea phytotoxin botcinic acid has also been studied and shown to have a redundant role in virulence with botrydial [14].

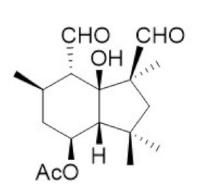

(1)

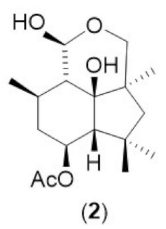

Figure 1. Chemical structures of botrydial (1) and dihydrobotrydial (2).

Even though photosensitization has been demonstrated to have significant antimicrobial efficiency against an array of microorganisms, there is limited literature available as to whether photosensitization will inhibit the growth of $B$. cinerea, and moreover the impacts of photosensitization on the production of the phytotoxic metabolites botrydial and dihydrobotrydial. Previous studies have investigated the antifungal effect of $405 \mathrm{~nm}$ light at $60 \mathrm{~mW} \mathrm{~cm}{ }^{-2}$ for $24 \mathrm{~h}$ on this phytopathogen [15]. These authors suggested that the excitation of endogenous porphyrins and subsequent accumulation of singlet oxygen contribute to the light-mediated photoinactivation of grey mould, and suggested such treatment as a means of controlling plant disease. Such lengthy irradiation would, however, not be appropriate with a food commodity such as strawberries, and moreover these authors did not examine the impacts of this treatment on the phytotoxic metabolites.

In this study, B. cinerea was isolated from Queensland (Australia) grown strawberries and used to evaluate the effects of photosensitization on the growth of this fungus under a range of experimental conditions including different concentrations of photosensitizer (curcumin), incubation time, and light dose with irradiation periods of 10-30 min. At the same time, a new high-resolution accurate mass (HRAM) UPLC-MS/MS method was developed and validated to study the relative formation of the metabolites botrydial and dihydrobotrydial under these photosensitization conditions. 


\section{Results}

\subsection{Extraction of Botrydial and Dihydrobotrydial from B. cinerea Cultures}

Solvent extraction of $B$. cinerea cultures obtained from Queensland strawberries provided a mixed sample of the fungal metabolites botrydial and dihydrobotrydial after repeated silica chromatography. Unfortunately, attempts to further purify these compounds resulted in further degradation of these metabolites. Botrydial and dihydrobotrydial are known compounds for which both ${ }^{1} \mathrm{H}$ and ${ }^{13} \mathrm{C}$ NMR have been reported [16,17], and literature data were used to both confirm the identity of the two components in our extract and also enabled quantification of the amount of each component within the mixed sample. Integration of ${ }^{1} \mathrm{H}$ NMR resonances with a measured aliquot of dioxane as internal standard were used to determine the amount of botrydial/dihydobotrydial present in the sample. The isolated mixed standard was determined to contain botrydial and dihydrobotrydial in a 1:9 ratio, and used without further purification as a mixed external standard in the development of and validation of a new HRAM UPLC-MS/MS analysis method for both metabolites.

\subsection{HRAM UPLC-MS/MS Analysis of Botrydial and Dihydrobotrydial}

HRAM UPLC-MS/MS analysis of the mixed botrydial/dihydobotrydial standard provided two peaks with molecular ions consistent with the molecular formula of the two components botrydial (1) $\left(\mathrm{C}_{17} \mathrm{H}_{27} \mathrm{O}_{5} ; \mathrm{M}+\mathrm{H}\right]^{+}$; Calc. 311.1853 Obs. 311.1858) and dihydrobotrydial (2) $\left(\mathrm{C}_{17} \mathrm{H}_{28} \mathrm{O}_{5} \mathrm{Na}\right.$; [M+Na] ${ }^{+}$; Calc. 335.1829 Obs. 335.1825) (Figure 2). Dihydrobotrydial did not provide a reliable molecular ion $[\mathrm{M}+\mathrm{H}]^{+}$in ESI+ mode, and $[\mathrm{M}+\mathrm{Na}]^{+}$was selected for analysis of this metabolite. $\mathrm{MS}^{2}$ fragmentation ions for each metabolite were selected from predominant ions in fragmentation spectra for each component (Figure 2).

(a)

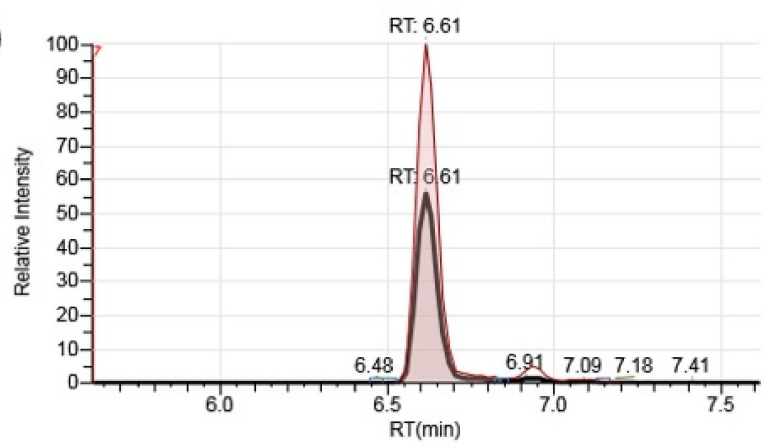

(c)

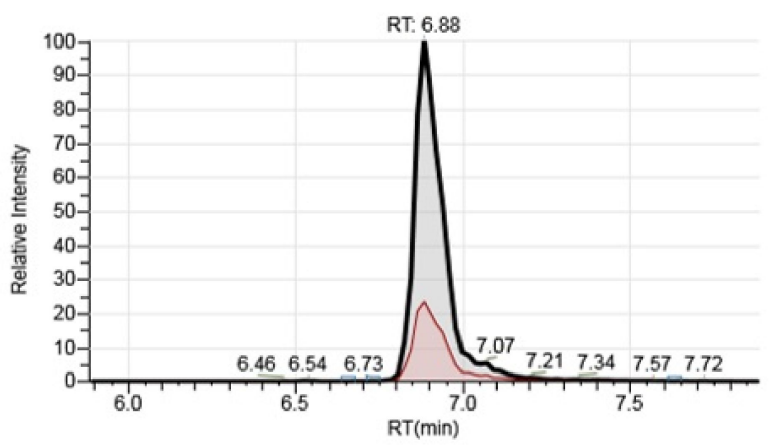

(b)

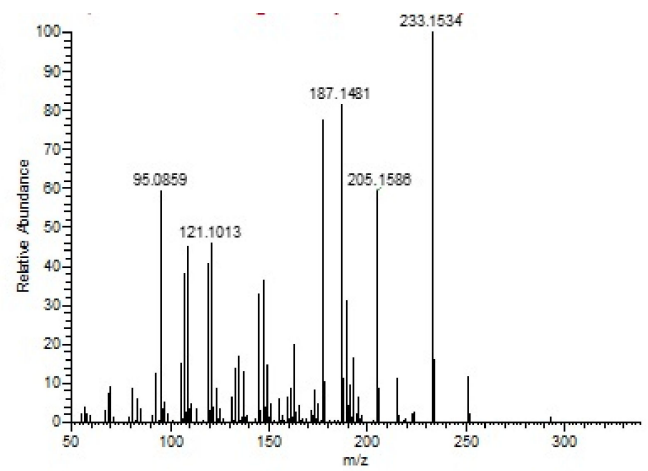

(d)

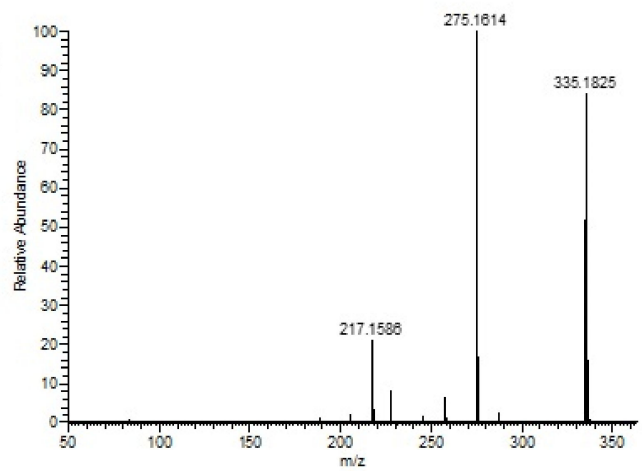

Figure 2. HRAM UPLC-MS/MS analysis of (a) botrydial $[\mathrm{M}+\mathrm{H}]^{+}$showing overlay of parallel reaction monitoring (PRM) transitions for quantification $(m / z 311.1853 \rightarrow 205.1586)$ and confirmation $(m / z 311.1853 \rightarrow 187.1481)$, and $(\mathbf{b})$ the major fragmentation ions of botrydial $[\mathrm{M}+\mathrm{H}]^{+}$at $35 \mathrm{NCE}$, together with (c) dihydrobotrydial $[\mathrm{M}+\mathrm{Na}]^{+}$overlay of PRMs for quantification $(m / z 335.1829 \rightarrow 275.1614)$ and confirmation $(m / z 335.1829 \rightarrow 217.1586)$ and $(\mathbf{d})$ the major fragmentation ions of dihydrobotrydial $[\mathrm{M}+\mathrm{Na}]^{+}$at $35 \mathrm{NCE}$. 
For botrydial in ESI+ mode, the major MS/MS fragmentation ions of $[\mathrm{M}+\mathrm{H}]^{+} \mathrm{m} / \mathrm{z}$ 311.1853 (Figure $2 \mathrm{~b}$ and Figure $\mathrm{S} 1$ ) corresponded to sequential losses: $[\mathrm{M}+\mathrm{H}-\mathrm{AcOH}]^{+}$ $\left(\mathrm{C}_{15} \mathrm{H}_{23} \mathrm{O}_{3} \text { Calc } 251.1647 \text { Obs. 251.1640), [M+H-AcOH-H }{ }_{2} \mathrm{O}\right]^{+}\left(\mathrm{C}_{15} \mathrm{H}_{21} \mathrm{O}_{2}\right.$ Calc 233.1542 Obs. 233.1534), further loss of $\mathrm{CO}\left(\mathrm{C}_{14} \mathrm{H}_{21} \mathrm{O}_{1}\right.$ Calc 205.1592 Obs. 205.1586) and an additional loss of either $\mathrm{H}_{2} \mathrm{O}$ to $\mathrm{C}_{14} \mathrm{H}_{19}$ (Calc 187.1487 Obs. 187.1481) or a second $\mathrm{CO}$ to $\mathrm{C}_{13} \mathrm{H}_{21}$ (Calc 177.1643 Obs. 177.1637). Such losses are consistent with a protonated form of the botrydial structure (1). For dihydrobotrydial in ESI+ mode the major MS/MS fragmentation ions of $[\mathrm{M}+\mathrm{Na}]^{+} m / z 335.1825\left(\mathrm{C}_{17} \mathrm{H}_{28} \mathrm{O}_{5}\right.$ Calc. 335.1829) (Figure 2d) corresponded to sequential losses [M+Na-AcOH] ${ }^{+}\left(\mathrm{C}_{15} \mathrm{H}_{24} \mathrm{O}_{3} \mathrm{Na}\right.$ Calc 275.1623 Obs. 275.1614), further loss of $\mathrm{NaOH}$ and $\mathrm{H}_{2} \mathrm{O}\left(\mathrm{C}_{15} \mathrm{H}_{21} \mathrm{O}_{1}\right.$ Calc 217.1592 Obs. 217.1586). Such losses are consistent with the dihydrobotrydial structure (2), and demonstrate attachment of the $\mathrm{Na}^{+}$ion within the hydroxy lactol arrangement of this compound.

Parallel reaction monitoring (PRM) transitions for botrydial (1) of $m / z 311.1853 \rightarrow$ 205.1586 and for dihydrobotrydial (2) of $m / z 335.1829 \rightarrow 275.1614$ were selected for quantification, with secondary transitions utilized for confirmation of botrydial (1) $(\mathrm{m} / z 311.1853$ $\rightarrow 187.1481$ and $m / z 311.1853 \rightarrow 233.1534)$ and dihydrobotrydial $(2)(m / z 335.1829 \rightarrow$ 217.1586). The calibration curves based on these quantification PRM responses were linear over the range 1.02-9.92 $\mu \mathrm{g} / \mathrm{L}$ for botrydial and 9.22-89.28 $\mu \mathrm{g} / \mathrm{L}$ for dihydrobotrydial. Rapid separation ( $<7 \mathrm{~min}$ ), good reproducibilities (average RSDs $<10 \%$ ), and good recoveries (77.2\% and 83.5\%) were obtained in the HRAM UPLC-MS/MS analysis of both botrydial (1) and dihydrobotrydial (2) from spiked agar plates (Table 1).

Table 1. Recovery of botrydial (1) and dihydrobotrydial (2) from $1 \mathrm{~cm}$ plugs of spiked agar as measured by HRAM UPLC-MS/MS ( $n=4$ at each concentration).

\begin{tabular}{ccccc}
\hline Metabolite & $\begin{array}{c}\text { Spiking Level } \\
\mu \mathrm{g} / \mathrm{g}\end{array}$ & $\begin{array}{c}\text { Detected Conc. } \\
( \pm \mathbf{S D}), \boldsymbol{\mu g} / \mathbf{g}\end{array}$ & Recovery, $( \pm$ SD), \% & RSD, \% \\
\hline Botrydial & 0.11 & $0.07(0.01)$ & $66.3(10.4)$ & 15.7 \\
& 1.02 & $0.84(0.04)$ & $81.6(4.3)$ & 5.3 \\
Average & 9.92 & $8.31(0.44)$ & $83.8(4.5)$ & 5.4 \\
\hline Dihydrobotrydial & & & $77.2(6.4)$ & 8.3 \\
\hline & 0.10 & $0.08(0.01)$ & $81.9(7.0)$ & 8.5 \\
Average & 0.98 & $0.92(0.06)$ & $93.5(6.1)$ & 6.5 \\
\hline
\end{tabular}

\subsection{The Effect of Different Curcumin Concentration on Curcumin-Mediated Photosensitization of B. cinerea}

The effect of increasing curcumin dye (D) concentrations with a photosensitization light dose $(\mathrm{L})$ of $120 \mathrm{~J} / \mathrm{cm}^{2}$ on $B$. cinera growth on agar plates incubated at $26^{\circ} \mathrm{C}$ for 8 days was investigated. The $B$. cinerea control $\mathrm{D}^{-} \mathrm{L}^{-}$treatment $\left(\mathrm{D}^{-}=\right.$no curcumin; $\mathrm{L}^{-}=$no light) and $\mathrm{D}^{-} \mathrm{L}^{+}$treatment (no curcumin, light dose $120 \mathrm{~J} / \mathrm{cm}^{2}$ ) produced characteristic prolific greyish-brown spores, and visible differences in fungal growth was readily apparent with increasing curcumin concentrations after photosensitization treatment and incubation for 8 days (Figure S2). With increasing curcumin concentration, the growth of $B$. cinerea decreased. When treated with a curcumin concentration above $800 \mu \mathrm{M}$ and a light does of $120 \mathrm{~J} / \mathrm{cm}^{2}$, the fungus was not able to survive (Figure S2). As shown in Figure 3, a significant percentage $(p<0.001)$ reduction in the spores was also observed when the spores were treated with curcumin-mediated photosensitization. Treatment with light or curcumin alone $\left(\mathrm{D}^{-} \mathrm{L}^{+}\right.$or $\left.\mathrm{D}^{+} \mathrm{L}^{-}\right)$was not effective. The curcumin-mediated photosensitization $\left(\mathrm{D}^{+} \mathrm{L}^{+}\right)$ reduction in spore germination was directly proportionate to curcumin concentrations, with increasing concentrations of curcumin photosensitizer acting to drastically inhibit $B$. cinerea conidia germination. With curcumin concentrations above $600 \mu \mathrm{M}$ and light dose of $120 \mathrm{~J} / \mathrm{cm}^{2}$, spore germination was completely $(100 \%)$ inhibited $(p<0.001)$ (Figure 3$)$. 


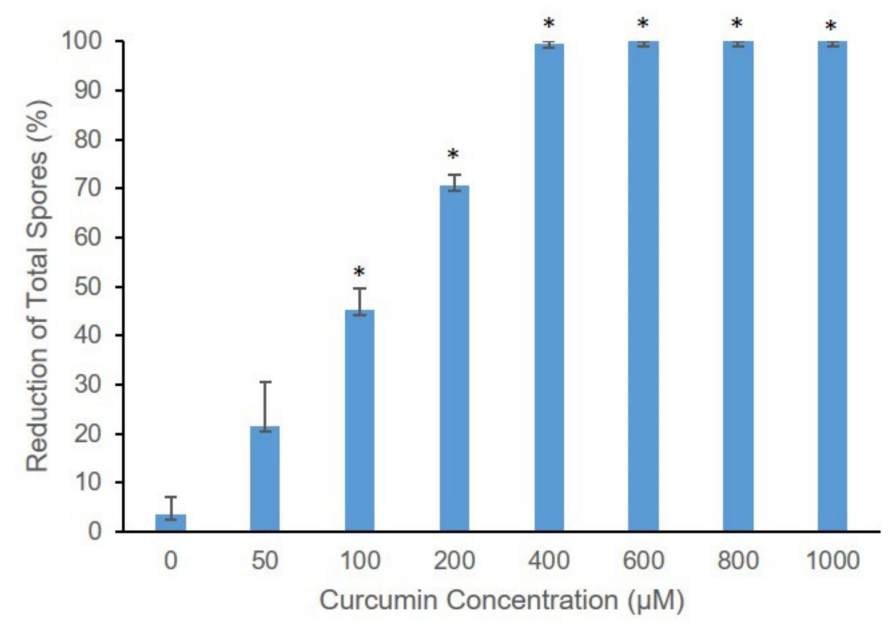

Figure 3. Effect of curcumin-mediated photosensitization on B. cinerea spore germination with different curcumin concentrations $(0-1000 \mu \mathrm{M})$ and light dose $120 \mathrm{~J} / \mathrm{cm}^{2}$ as represented by percentage reduction in total spores after incubation at $26{ }^{\circ} \mathrm{C}$ for 8 days. The significance of difference in mean colony counts (CFU) between different curcumin concentration and control $\left(\mathrm{D}^{-} \mathrm{L}^{-}\right)$are indicated by asterisk $\left(^{*}\right)$; where $p<0.001$ tested with $t$-test.

As shown in Figure 4a, increasing curcumin concentration from 0 to $200 \mu \mathrm{M}$ in the photosensitization treatment resulted in no significant change in botrydial concentration after 11 days incubation at $26{ }^{\circ} \mathrm{C}$, although there was an overall trend of decreasing dihydrobotrydial (Figure $4 \mathrm{~b}$ ). However, with a curcumin concentration of $400 \mu \mathrm{M}$, the fungal production of both botrydial and dihydrobotrydial was significantly reduced $(p<0.05)$, compared to control or light alone $\left(\mathrm{D}^{-} \mathrm{L}^{-}\right.$or $\left.\mathrm{D}^{-} \mathrm{L}^{+}\right)$. The control treatment $\left(\mathrm{D}^{-} \mathrm{L}^{-}\right)$contained botrydial and dihydrobotrydial at measured concentrations of $5.57 \pm 1.13 \mu \mathrm{g} / \mathrm{g}$ and $140.50 \pm 45.87 \mu \mathrm{g} / \mathrm{g}$, respectively, providing a dihydrobotrdial/botrydial ratio of 25:1 (Figure 4c). The ratio of dihydrobotrdial/botrydial decreased with increasing curcumin concentration reaching a ratio of 10.3:1 with a curcumin concentration of $400 \mu \mathrm{M}$ (Figure 4c). With curcumin concentration of $600 \mu \mathrm{M}$ or greater at light dose of $120 \mathrm{~J} / \mathrm{cm}^{2}$, no production of either botrydial or dihydrobotrydial was detected (Figure 4). 

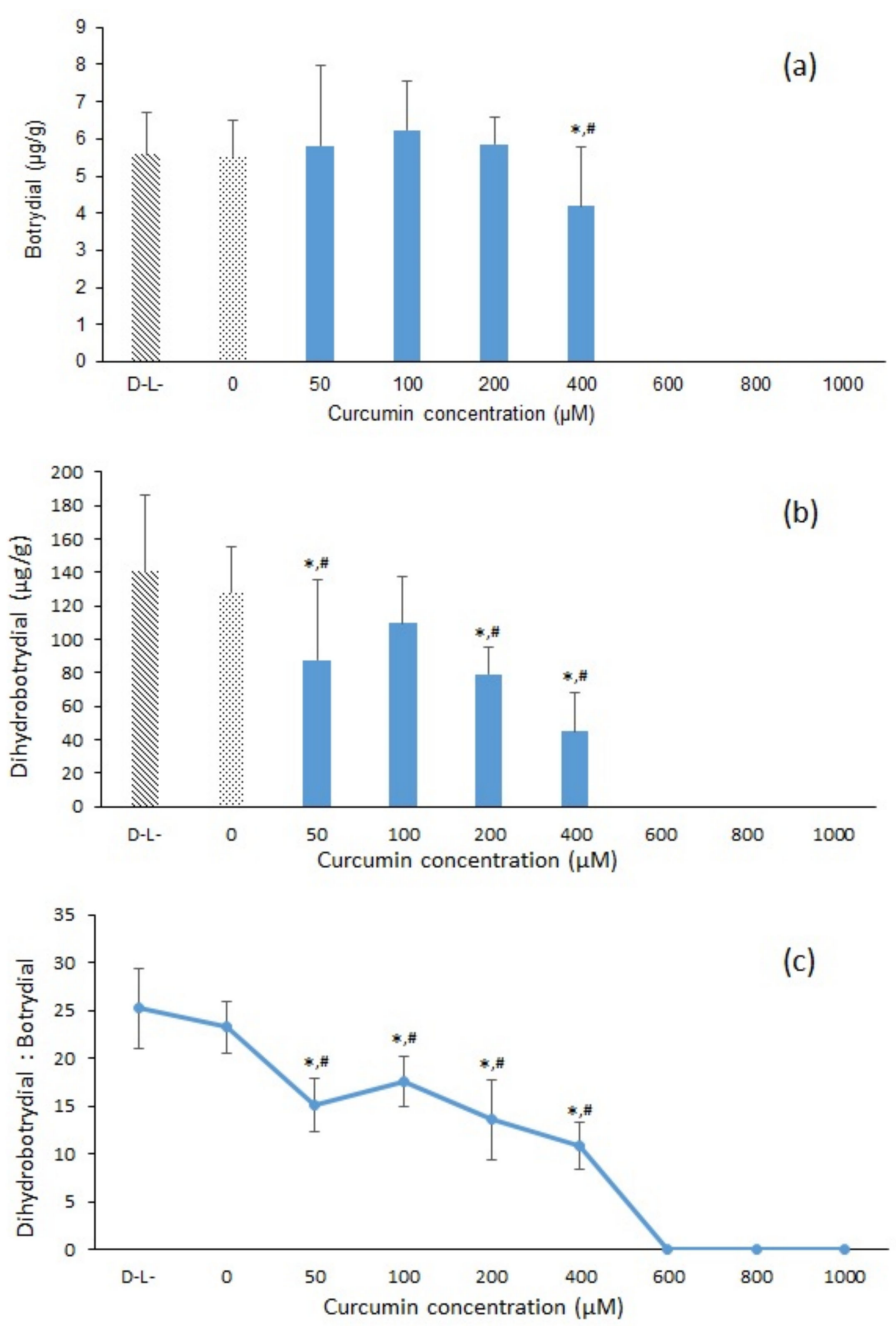

Figure 4. Effect of curcumin-mediated photosensitization with different curcumin concentrations $(0-1000 \mu \mathrm{M})$ and light dose $\left(120 \mathrm{~J} / \mathrm{cm}^{2}\right)$ on the concentration of botrydial and dihydrobotrydial in spores after incubation at $26{ }^{\circ} \mathrm{C}$ for 11 days $(n=6)$. The significances of difference in concentration of (a) botrydial and (b) dihydrobotrydial and ratio of (c) dihydrobotrdial/botrydial between different curcumin concentrations and light-only treatment $\left(\mathrm{D}^{-} \mathrm{L}^{+}\right.$, curcumin $\left.=0 \mu \mathrm{M}\right) p<0.05\left(^{*}\right)$, and compared to the control $\left(\mathrm{D}^{-} \mathrm{L}^{-}\right) p<0.05\left({ }^{\#}\right)$, tested with $t$-test.

\subsection{Effect of Curcumin-Mediated Photosensitization on the B. cinerea Spore Using Different Light Doses}

As shown in Figure S3, when treated with a light dose of $120 \mathrm{~J} / \mathrm{cm}^{2}$ and curcumin concentration of $800 \mu \mathrm{M}$, no spore germination was observed, which indicates that the spores were completely inactivated by this photosensitization mediated curcumin treatment. By comparison, the spores grew well after treatment with $800 \mu \mathrm{M}$ curcumin without light $\left(\mathrm{D}^{+} \mathrm{L}^{-}\right)$and under control conditions $\left(\mathrm{D}^{-} \mathrm{L}^{-}\right)$. The percentage reduction in total spores reached $100 \%$ with the curcumin-mediated light doses of 120,240 , and $360 \mathrm{~J} / \mathrm{cm}^{2}$ (Figure 5). Similarly, neither botrydial nor dihydrobotrydial could be detected when light and dye $\left(\mathrm{D}^{+} \mathrm{L}^{+}\right)$are used at the same time with light doses of 120,240 and $360 \mathrm{~J} / \mathrm{cm}^{2}$ (Figure 6). The botrydial concentration was observed to increase slightly from $6.2 \pm 2.2$ to $8.5 \pm 0.9 \mu \mathrm{g} / \mathrm{g}$ in the curcumin-only treatment $\left(\mathrm{D}^{+} \mathrm{L}^{-}\right)$, comparing to the control $\left(\mathrm{D}^{-} \mathrm{L}^{-}\right)$ $(p<0.05)$. However, the dihydrobotrydial concentration was not significantly different between the curcumin-only treatment $\left(\mathrm{D}^{+} \mathrm{L}^{-}\right)$and the control $\left(\mathrm{D}^{-} \mathrm{L}^{-}\right)$(Figure 6$)$. 


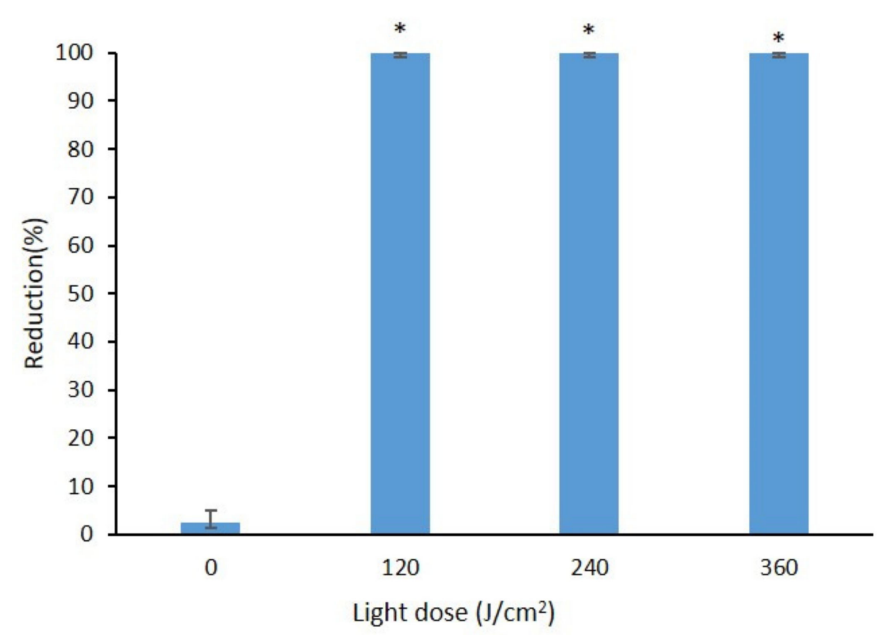

Figure 5. Effect of photosensitization mediated curcumin on the B. cinerea spore with curcumin concentration of $800 \mu \mathrm{M}$ using different light dose $\left(0,120,240,360 \mathrm{~J} / \mathrm{cm}^{2}\right)$ as represented by percentage reduction in total spores after incubation at $26^{\circ} \mathrm{C}$ for 11 days. The significance of difference in mean number of colonies between different light dose and control $\left(\mathrm{D}^{-} \mathrm{L}^{-}\right)$for each light dose are indicated by asterisk where $\left(^{*}\right) ; p<0.001$ tested with $t$-test.

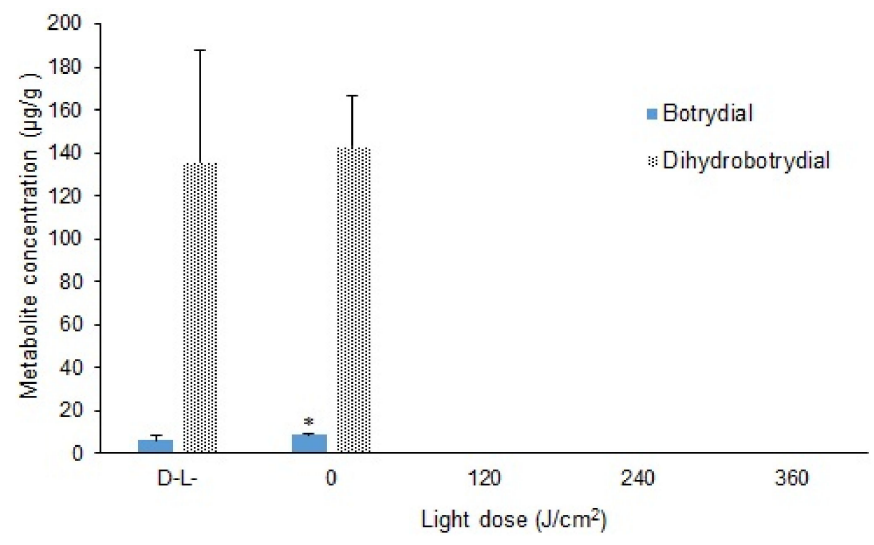

Figure 6. The concentration of botrydial and dihydrobotrydial in the different light dose treatments $\left(0,120,240,360 \mathrm{~J} / \mathrm{cm}^{2}\right)$ with curcumin concentration of $800 \mu \mathrm{M}$ after incubation at $26^{\circ} \mathrm{C}$ for 11 days. The significance of difference in concentration of botrydial and dihydrobotrydial between control $\left(\mathrm{D}^{-} \mathrm{L}^{-}\right)$and only curcumin $\left(\mathrm{D}^{+} \mathrm{L}^{-}\right.$, light dose $\left.0 \mathrm{~J} / \mathrm{cm}^{2}\right)(n=9)$ are indicated by asterisk where $\left(^{*}\right)$; $p<0.05$, tested with $t$-test. Neither botrydial nor dihydrobotrydial was detected with light doses of 120,240 or $360 \mathrm{~J} / \mathrm{cm}^{2}$.

\subsection{The Growth of B. cinerea over Different Incubation Time After Photosensitization}

In studies of effect of different treatments on $B$. cinerea with increasing incubation time (Figure S4), it was observed that in the control treatment $\left(\mathrm{D}^{-} \mathrm{L}^{-}\right)$mycelial growth was fast with white hyphae apparent within two days incubation. With prolonging incubation time, the three treatments $\left(\mathrm{D}^{-} \mathrm{L}^{-} ; \mathrm{D}^{-} \mathrm{L}^{+} ; \mathrm{D}^{+} \mathrm{L}^{-}\right)$display the expected regular fungi morphology. In contrast, with the curcumin treatment $\left(\mathrm{D}^{+} \mathrm{L}^{+}\right)$, the spores did not germinate during the 16 days incubation. As shown in Figure 7, in general the light-only and dye-only treatments $\left(\mathrm{D}^{-} \mathrm{L}^{+}\right)$and $\left(\mathrm{D}^{+} \mathrm{L}^{-}\right)$demonstrated a general increase in production of both secondary metabolites reaching $8.31 \pm 0.54$ and $11.18 \pm 1.53 \mu \mathrm{g} / \mathrm{g}$ of botrydial, and $179.69 \pm 30.04$ and $205.29 \pm 53.71 \mu \mathrm{g} / \mathrm{g}$ of dihydrobotrydial, respectively, at 15 days. The control treatment $\left(\mathrm{D}^{-} \mathrm{L}^{-}\right)$produced a more variable botrydial concentration (Figure 7 ) with a maximum of $7.41 \pm 3.56 \mu \mathrm{g} / \mathrm{g}$. At all incubation times, all samples from treatment $\left(\mathrm{D}^{+} \mathrm{L}^{+}\right)$were below limits of detection for both botrydial and dihydrobotrydial (Figure 7), which is most likely due to the destruction of all $B$. cinerea spore by this treatment. In order to eliminate 
interference due to variability between plates, the ratio of dihydrobotrydial/botrydial was also calculated. The average metabolite ratio in the three treatments $\left(\mathrm{D}^{-} \mathrm{L}^{-} ; \mathrm{D}^{-} \mathrm{L}^{+} ; \mathrm{D}^{+} \mathrm{L}^{-}\right)$ is $19.42 \pm 3.62,21.83 \pm 3.52$ and $15.34 \pm 3.20$, respectively.

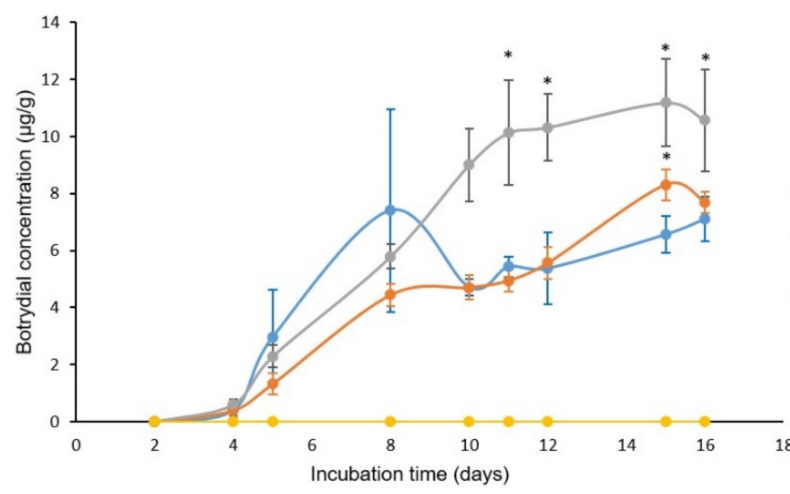

(a)

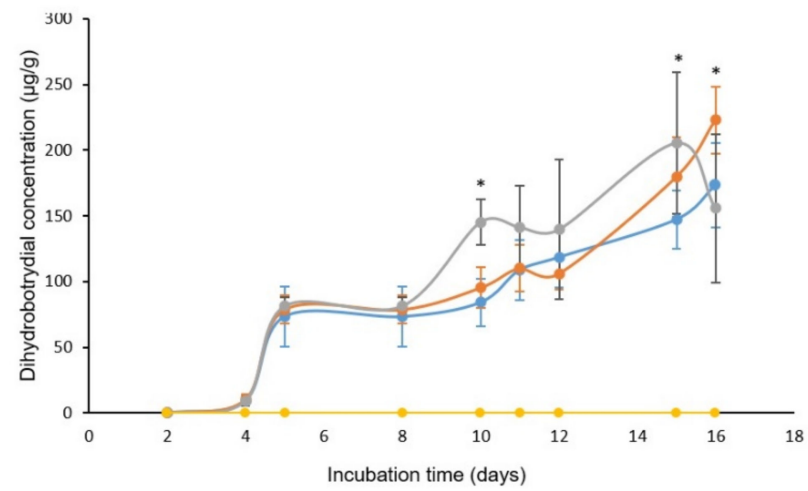

(b)

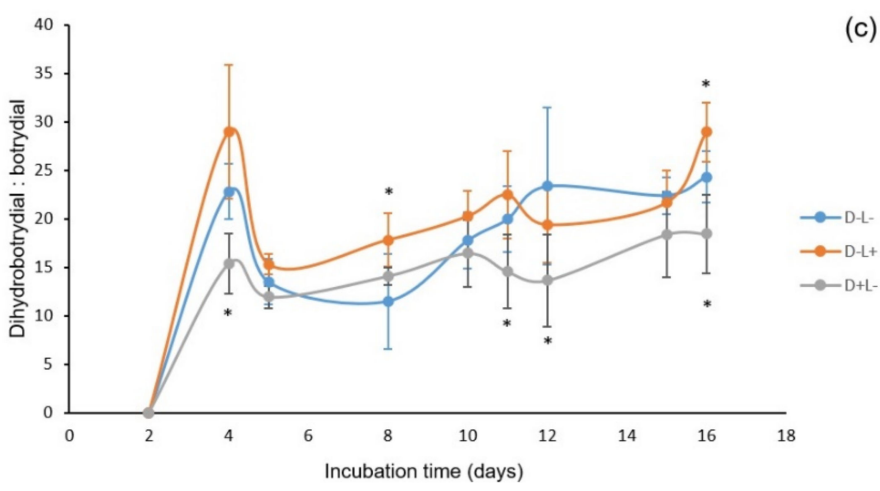

Figure 7. The concentration of botrydial and dihydrobotrydial after using different treatment regimes of $\mathrm{D}^{+} \mathrm{L}^{+}$: curcumin $(800 \mu \mathrm{M})$ and light $\left(120 \mathrm{~J} / \mathrm{cm}^{2}\right) ; \mathrm{D}^{-} \mathrm{L}^{-}$(control): no curcumin and no light; $\mathrm{D}^{-} \mathrm{L}^{+}$: no curcumin and light $\left(120 \mathrm{~J} / \mathrm{cm}^{2}\right) ; \mathrm{D}^{+} \mathrm{L}^{-}$: curcumin $(800 \mu \mathrm{M})$ and no light followed by incubation at $26^{\circ} \mathrm{C}$ for $0-16$ days. The significances of difference in concentration of botrydial and dihydrobotrydial between treatment and $\mathrm{D}^{-} \mathrm{L}^{-}$(control) $(n=6)$ are indicated by asterisk where $\left(^{*}\right)$; $p<0.05$, tested with $t$-test. (a) Botrydial concentration in different treatment; (b) Dihydrobotrydial concentration in different treatment; (c) The ratio of dihydrobotrydial and botrydial concentrations in different treatment, $\mathrm{D}^{+} \mathrm{L}^{+}$not included as neither metabolite detected.

\section{Discussion}

\subsection{LC-MS/MS Analysis of Metabolites Botrydial and Dihydrobotrydial}

High-resolution accurate mass (HRAM) spectrometers, such as the time-of-flight (TOF) and the Orbitrap spectrometer, has become more accessible and affordable to many laboratories in recent years. One of the biggest strengths of a HRAM instrument is its ability to acquire accurate mass data, which allows the user to relate the observed accurate mass to an equivalent elemental composition/s and molecular formula/s. Molecular formulas 
alone, however, are not sufficient to identify specific compounds. Without applicable standards, erroneous identifications can result due to the many possible compounds with the same molecular formula, and for this reason we have chosen to isolate authentic botrydial/dihydrobotrydial to use as standards in this study. These metabolites are not commercially available but can be obtained from B. cinerea cultures as described here.

Literature reports of UPLC-MS/MS analysis of similar authentic botrydial standards are lacking, but there are two recent literature reports on the detection of botrydial through the untargeted HRAM approach. Niedzwiecki et al. [18] studied the metabolomics from the human suction blister fluid and among their analytes observed the accurate masses of 333.1672 $\mathrm{Da}$ and 328.2118 Da which they attributed to $[\mathrm{M}+\mathrm{Na}]^{+}$and $\left[\mathrm{M}+\mathrm{NH}_{4}\right]^{+}$molecular ions of botrydial. El Fellah et al. [19] analysed drinking water from Finland, gave a detailed account including $\mathrm{MS}^{2}$ fragmentations of the protonated molecular ion $[\mathrm{M}+\mathrm{H}]^{+}$ $\mathrm{C}_{17} \mathrm{H}_{27} \mathrm{O}_{5}(\mathrm{~m} / z: 311.18 \rightarrow 311.18454 ; 311.18 \rightarrow 293.17410 ; 311.18 \rightarrow 265.17929 ; 311.18 \rightarrow$ 255.12225 and $311.18 \rightarrow 237.11171)$ which they ascribed to botrydial. These authors used the co-detection of a second component identified on the basis of accurate mass $\left(\mathrm{C}_{15} \mathrm{H}_{21} \mathrm{O}_{4}\right.$, 265.1434) as abscisic acid, a compound also associated with $B$. cinerea fungi, to support the identification of botrydial in their water samples. Authentic botrydial and abscisic acid standards were stated to be not available and identification was based on 'accurate mass method with UHPLC-HRMS'. Notably however according to SciFinder searches, there are 1648 different compounds known with molecular formulae $\mathrm{C}_{17} \mathrm{H}_{26} \mathrm{O}_{5}$. Each of these 1648 compounds would exhibit the same $[\mathrm{M}+\mathrm{H}]^{+} 311.1853 \mathrm{Da}\left(\mathrm{Calc}\right.$ for $\left.\mathrm{C}_{17} \mathrm{H}_{27} \mathrm{O}_{5}\right)$ but expected fragmentation would be different. On the basis of HRAM, the sequential losses reported by El Fellah et al. [19] can be ascribed as follows $m / z 311.18 \rightarrow 293.17410$ loss of $\mathrm{H}_{2} \mathrm{O} ; m / z$ $311.18 \rightarrow 265.17929$ loss of $\mathrm{H}_{2} \mathrm{O}$ and $\mathrm{CO} ; m / z 311.18 \rightarrow 255.12225$ loss of $\mathrm{CO}$ and $\mathrm{CO}$; and $m / z 311.18 \rightarrow 237.11171$ loss of $\mathrm{H}_{2} \mathrm{O}$ and $2 \times \mathrm{CO}$. Notably, no loss of $\mathrm{AcOH}$ was observed, which in itself is inconsistent with botrydial structure (as is the loss of $2 \times \mathrm{CO}$ without loss of $\mathrm{H}_{2} \mathrm{O}$ ). The $\mathrm{MS}^{2}$ fragmentations of the metabolite detected by El Fellah et al. [19] is seemingly different to that of our authenticated botrydial (Figures 2 and S1), and casts doubt on the water analysis results published in their report. Similarly the $[\mathrm{M}+\mathrm{Na}]^{+}$and $\left[\mathrm{M}+\mathrm{NH}_{4}\right]^{+}$molecular ions reported by Niedzwiecki et al. [18] are not unique to botrydial and may or may not be actually botrydial.

Coincidentally, both the study by El Fellah et al. [19] and the current investigation were conducted on the Orbitrap mass spectrometer platform with similar elution solvent systems. We, however, find the HRAM approach not ideal for the detection of botrydial (without standard) as accurate mass fragmentation data in the literature is lacking to support the direct identification of botrydial by accurate mass alone. During our own investigations we frequently noted a second background contaminant in our samples and/or in our LCMS system which unexpectedly gives an accurate mass which is in agreement with the $[\mathrm{M}+\mathrm{H}]^{+}$molecular ion of botrydial under 5 ppm mass errors. This background compound did not co-elute with our authentic botrydial standard, nor did it exhibit the same MS fragmentation as our authenticated botrydial despite apparently having the same molecular formula accordingly to HRAM data. Consequently, without a botrydial standard we find it unreliable to identify botrydial based purely on the untargeted accurate mass data. Interestingly, dihydrobotrydial, which is a detoxification by-product of botrydial, was not reported from the two previous HRAM studies $[18,19]$. With the obvious gap in the untargeted HRAM detection of botrydial, we have isolated the two diagnostic metabolites, botrydial and dihydrobotrydial, from B. cinerea and have provided here detailed HRAM and MS ${ }^{2}$ accurate mass data for future comparison (Figures 2 and S1). The new analysis method described here also demonstrated good reproducibility and reliability in recoveries of both botrydial and dihydrobotrydial from spiked agar plates (Table 1), enabling the use of this method to study effects of photosensitization on B. cinerea metabolite production. 


\subsection{Effect of Curcumin-Mediated Photosensitization on B. cinerea}

This study demonstrated that the use of curcumin followed by irradiation with blue light $(430 \mathrm{~nm})$ promoted a significant reduction in the germination of $B$. cinerea. This result is in agreement with previous studies that have reported similar effects of curcumin and other photosensitizers with different food-borne pathogens. For example, Penha et al. [4] reported that curcumin $(75 \mu \mathrm{M})$ and blue illumination $(470 \mathrm{~nm})$ had synergistic effect on inactivation of food-borne pathogens with relative order of efficacy Aeromonas hydrophila $>$ Salmonella aureus $>$ Escherichia coli $>$ Salmonella typhimurium. Josewin et al. [20] similarly utilized blue light-emitting diodes $(405-460 \mathrm{~nm})$ with sodium chlorophyllin as photosensitizer to inactivate Listeria monocytogenes and Salmonella spp., minimizing the contamination risk of food-borne pathogens by consumption of cantaloupe. These authors achieved similar reductions with and without added photosensitizer on cantaloupe rind and speculated about the presence of an endogenous photosensitizer [20]. Our research group found that curcumin combined with visible light $(420 \mathrm{~nm})$ was an effective treatment to inactivate spores of Aspergillus flavus both in vitro and in vivo in maize kernels [5,21]. In subsequent studies, the percentage reduction in Aspergillus niger, A. flavus, Penicillium chrysogenum and Zygosacharomyces bailii remained above $50 \%$ with curcumin concentrations (100 to $400 \mu \mathrm{M})$ followed by illumination with a light dose of $96 \mathrm{~J} / \mathrm{cm}^{2}$ [22]. In the present study, at low curcumin concentration (50 to $400 \mu \mathrm{M})$ and under a similar light dosage, the percentage reduction in B. cinerea varied from 21.5 to $99.7 \%$, which may reflect the differing susceptibility of the fungal species studied. Penicillium griseofulvum by comparison demonstrated less susceptibility in previous studies [22], than that recorded here for $B$. cinerea. In all cases, the phototoxic effect seems to depend on the curcumin concentration, which is in agreement with the previous reports [23]. Fungi are usually enveloped by a thick rigid cell wall, which is made of chitin, mannoproteins and $\alpha-\beta$ glucans, and photoinactivation is therefore dependent on photosensitizer uptake through this cell wall and distribution to subcellular targets [24]. The phototoxicity of curcumin is then directed through reactive oxygen species formed by the reaction between the light-activated dye molecules and the excited states of oxygen molecules [25]. Sanita et al. [26] reported that photodynamic therapy mediated by curcumin associated with LED light significantly reduced the metabolism of the biofilm organized cells of Candida dubliniensis. They also reported that exposure to curcumin alone in the highest concentrations (30 and $40 \mu \mathrm{M})$ significantly reduced the biofilm viability. Further, while curcumin was rapidly taken up by Candida dubliniensis cells, curcumin was reported to require a longer time interval to penetrate into biofilm cells [26]. Araujo et al. [23] reported that curcumin has a toxic effect on cariogenic pathogens only at appreciable concentrations $(5.0 \mathrm{~g} / \mathrm{L})$ upon photoactivation. Providentially, curcumin is a food additive (E100) and a naturally polyphenol extracted from Curcuma longa with no significant reported toxicity, well-known for its beneficial biological activities, including antimicrobial anti-proliferative, anti-inflammatory and antioxidant activities $[27,28]$. From an economic viewpoint, curcumin can be produced in high quantities at a reasonable cost, so it is an ideal photosensitizer. However, curcumin is a very hydrophobic molecule and requires some kind of formulation vehicle to enable higher curcumin load and improve interaction between dissolved curcumin and cell membranes [29]. For consumer acceptance any change in flavour and colour of the treated commodity as a result of curcumin addition would also need to be considered.

The present study also evaluated the effect of different exposure time or light dose on curcumin-mediated photosensitization of $B$. cinerea and demonstrated that only a short 10 min period of illumination was required. The $\mathrm{D}^{+} \mathrm{L}^{+}$treatment achieved complete inactivation of $B$. cinerea when utilizing $800 \mu \mathrm{M}$ curcumin and illumination time of $10 \mathrm{~min}$, equivalent to a light dose of $120 \mathrm{~J} / \mathrm{cm}^{2}$ (Figure 5). This result is analogous to previous studies with other microbial species. For example, Penh et al. [4] reported that with increasing the illumination time (10 to $30 \mathrm{~min}$ ) or light does $\left(139\right.$ to $\left.417 \mathrm{~J} / \mathrm{cm}^{2}\right)$, curcuminmediated photosensitization induced a significant reduction in the counts of Gram-positive and Gram-negative bacteria, such as S. aureus, Pseudomonas aeruginosa and Aeromonas 
hydrophila. Similarly, Araujo et al. [23] reported that a curcumin illumination time of 2 or 5 min was equally effective in reducing Streptococcus mutans and Lactobacillus acidophilus. It is, however, worth noting that some researchers have observed photobleaching with consequent decreases in effectiveness with increased photosensitization illumination times. For example, in evaluation of photodynamic therapy using a curcumin solution on root canals contaminated with Enterococcus faecalis, curcumin as sensitizer was effective with 5 min irradiation but not with 10 min irradiation, which the authors related to curcumin photobleaching [30].

This current study aimed at the identification of the most effective curcumin-mediated photosensitization treatment against $B$. cinerea. Therefore, the $B$. cinerea morphology was observed for a period of 16 days after treatment with a light does of $120 \mathrm{~J} / \mathrm{cm}^{2}$ and curcumin concentration of $800 \mu \mathrm{M}$. In comparison to curcumin-only or light-only treatment $\left(\mathrm{D}^{+} \mathrm{L}^{-}\right.$and $\left.\mathrm{D}^{-} \mathrm{L}^{+}\right)$, this study demonstrated that curcumin-mediated photosensitization $\left(\mathrm{D}^{+} \mathrm{L}^{+}\right)$not only influences the mycelial growth of $B$. cinerea, but also causes a delay or inhibition in the germination of the fungal spore population. Curcumin has been reported to exhibit antifungal activity against Cryptococcus neoformans, Phytophthora infestans, Rhizoctonia solani, Candida albicans, and Erysiphe graminis [31,32]. In addition, phototherapy has been suggested as a potential therapeutic alternative to antifungal treatment for the treatment of C. albicans biofilm infections. Many studies have demonstrated that blue light (a wavelength of 400-500 nm) alone exhibits significantly antimicrobial effects against methicillin-sensitive S. aureus [33], Acinetobacter [34] and C. albicans [35]. However, in the present study, neither curcumin nor light alone was effective in eliminating $B$. cinerea, which is a similar conclusion to the previous reports with A. flavus [21].

The exact mechanism of the photosensitizer inducer photodynamic inactivation has not been elucidated. However, many researchers believe that the photosensitization method is based on combined action of photosensitizer, visible light, and oxygen, producing the observed cytotoxic effect [36], in which light-activated photosensitizers transfer energy to oxygen to form reactive oxygen species and other free radicals which inactivate microorganisms by damaging proteins, cell membranes, and organelles [37].

In the present study, the effects of photosensitization on B. cinerea phytotoxin production were also considered. Phytotoxins, including alkaloids, terpenes, polyketides, non-ribosomal peptides, or metabolites of mixed biosynthetic origin, are secreted by necrotrophic pathogens to induce cell necrosis and leakage of nutrients [38]. B. cinerea is one of most broad-host range fungal necrotrophs, and infects a large number of vegetables and fruit crops with subsequent economic loss both pre- and post-harvest. B. cinerea produces phytotoxins, ROS, as well as cell wall-degrading enzymes to induce necrosis of plant tissues. B. cinerea is also reported to trigger hypersensitive responses and ROS production in the host, which cause a series of programmed cell death to promote the infection process [39]. Botrydial is the primary phytotoxic sesquiterpene metabolite secreted by $B$. cinerea, and triggers ROS production, hypersensitive response, and expression of defence genes. Therefore, it is considered that botrydial may act not only as a phytotoxin, but also as an elicitor of plant defence responses [40,41]. For this reason, botrydial, as well as other B. cinerea-originated sesquiterpene metabolites, is regarded as an economically important fungal toxin for agriculturally and ornamental crops [11]. Although dihydrobotydial has only moderate phytotoxic activity at high concentrations [40], it is one of the major $B$. cinerea metabolites and co-occurs with botrydial during isolation [13]. The inhibition of the growth of $B$. cinerea has also been reported to be directly proportional to the botrydial concentration, with $B$. cinerea transforming botrydial to the less active phytotoxins such as dihydrobotrydial, botryenedial, and secobotrytrienediol [42]. Therefore, both botrydial and dihydrobotrydial were chosen in the present study as detection index to investigate the function of our photodynamic treatment.

Measured metabolite concentrations in the present study did not exactly mirror the effects of photodynamic degradation of $B$. cinerea spores. With increasing concentration of curcumin between 0 and $200 \mu \mathrm{M}$, the botrydial concentration remained relatively 
unchanged despite the inhibition of fungal growth (Figure 4). However, when the concentration of curcumin was raised above $200 \mu \mathrm{M}$, the botrydial concentration decreased and the fungi growth was also inhibited. Interestingly the production of dihydrobotrydial was more impacted at the lower curcumin concentrations. One explanation is that fungal growth may cease or be inhibited as a result of relatively higher botrydial with lesser colonies and with the increase in the concentration of curcumin. Duran-Patron et al. [42] similarly commented on the complexity of botrydial degradation pathways, with botrydial production during initial fungal growth stages regulating growth at higher concentrations, and metabolism to less inhibitory compounds, such as dihydrobotrydial, allowing growth to resume. It is noted that the botrydial concentrations measured in our agar plates (Figure 7) are less than one tenth of the maximal botrydial levels reported in the liquid culture studies of Duran-Patron et al. [42], and have not reached the levels reported by Duran-Patron et al. to regulate fungal growth. On the other hand, light-only $\left(\mathrm{D}^{-} \mathrm{L}^{+}\right)$or curcumin-only $\left(\mathrm{D}^{+} \mathrm{L}^{-}\right)$treatments may also effect the $B$. cinerea metabolite production, as seen in the varied ratio of dihydrobotrydial and botrydial produced (Figure 7). Lineiro et al. [43] found that there is a connection between gene expression of virulence factors and $B$. cinerea culture and environmental conditions, whereby the botrydial biosynthesis can be inhibited when the culture uses a sole carbon, such as cellulose and tomato cell walls. Similarly, when the spore suspension was treated with either light or curcumin in this study, this change in B. cinerea culture conditions could lead to a changed relationship between the metabolites botrydial and dihydrobotrydial (and consequently the ratio of these metabolites).

In the food industry, the most widely employed postharvest fruit protection methods to reduce microbial spoilage include chemicals and physical methods such as controlled atmosphere, low temperature or modified atmosphere packaging. Photosensitization as an environmentally friendly method, represents a potential novel technology with application in food and beverage industries. De Oliveira et al. [44] reported that combination of UV-A light and curcumin can significantly reduce bacterial cross-contamination of fresh produce. Tao et al. [45] reported curcumin-based photosensitization inactivate E. coli on the surface of apple slices and preserve the quality of apple slices. Our in vitro study has demonstrated the effectiveness of curcumin-mediated photosensitization against $B$. cinerea, a common fruit and vegetable pathogen. Further studies are required to investigate the effectiveness of this treatment against $B$. cinerea in fresh fruit such as strawberries. Promisingly, recent studies in Australian-grown strawberries demonstrated that photosensitization extended the shelf-life and did not affect the physicochemical quality of the strawberry and retained key quality attributes [9].

\section{Conclusions}

The observed reduction in B. cinerea spore germination was directly proportionate to curcumin concentrations, and both botrydial and dihydrobotrydial decreased with increasing curcumin concentration. In the treatment of $\mathrm{D}^{+} \mathrm{L}^{+}$with an illumination time of $10 \mathrm{~min}$ at curcumin concentration of $800 \mu \mathrm{M}$, the spores were completely inhibited and these botryane secondary metabolites could not be detected even after 16 days incubation. Under the other three treatments $\left(\mathrm{D}^{-} \mathrm{L}^{-}, \mathrm{D}^{-} \mathrm{L}^{+}\right.$and $\left.\mathrm{D}^{+} \mathrm{L}^{-}\right)$, the spores grew normally, with both botrydial and dihydrobotrydial being produced throughout the 16 days incubation period. Curcumin-mediated photosensitization therefore represents a potentially effective method to control B. cinerea infection, and warrants further investigation in vivo in susceptible fruit and vegetables.

\section{Materials and Methods}

\subsection{Fungal Materials}

Five filamentous fungi (Botrytis cinerea, Pestalotiopsis theae, Cladosporium sp., Penicillium raistrickii and Mucor rudolphii) were isolated and identified from four commercial varieties (Fortuna, Festival, Ruby Gem and Red Rhapsody) of strawberries grown on a Queensland 
farm, Australia. A randomly selected sample of ten fruits was washed thrice with potable water, and drained on clean paper towels. Then, each fruit was cut into four equal pieces using a sterilized scalper, and placed on potato dextrose agar (PDA) (Thermo Fisher Scientific, Victoria, Australia) plates. The plates were incubated at $25^{\circ} \mathrm{C}$. The samples were observed daily in a laminar flow cabinet for any fungal growth, and fungi were isolated as they appear on the cut pieces using sterile needles. B. cinerea isolated from these strawberries was identified by colony morphology. Pure cultures were observed under a light microscope (Leica, Germany) after staining with cotton blue lactophenol [46]. Identification was confirmed by performing $18 \mathrm{~S}$ rDNA analysis, as previously described [47]. Specifically, the fungus was cultured on Czapek Dox agar (Thermo Fisher Scientific, Victoria, Australia) at $26^{\circ} \mathrm{C}$ for 15 days, and the spores were harvested by flooding the plate with $10-15 \mathrm{~mL}$ $0.1 \%$ Tween 80 solution. The spore solution was then filtered through sterilized double folded cheesecloth to remove the hyphal fragments. The spore solution was diluted with sterile distilled water, and concentration determined by plating $0.1 \mathrm{~mL}$ aliquots of ten-fold dilutions on Dichloran Rose-Bengal Chloramphenicol Agar (DRBC) (Thermo Fisher Scientific, Victoria, Australia). The spores were stored in $15 \%$ glycerine at $-20{ }^{\circ} \mathrm{C}$. For the photosensitization experiments, spore suspensions of $10^{4} \mathrm{CFU}$ per $\mathrm{mL}$ were used, and cultured on Czapek Dox agar.

\subsection{Isolation of Botrydial and Dihydrobotrydial Standards}

Isolation of fungal metabolites was based on an adaption of the method of Lineiro et al. [43]. B. cinerea was grown on PDA culture for 3 days and then transferred to individual $500 \mathrm{~mL}$ reagent bottles ( 20 bottles, $3 \times 1 \mathrm{~cm}$ plugs of agar, ca. $0.75 \mathrm{~g}$ per bottle), each containing about $250 \mathrm{~mL}$ modified Czapek-Dox medium, which were continuously shaken at $250 \mathrm{rpm}$ under constant room temperature $\left(22^{\circ} \mathrm{C}\right)$ with $12 \mathrm{~h} \mathrm{light/dark}$ cycles for 13 days. All the liquid broths were combined (ca. $4.8 \mathrm{~L}$ ) and then extracted with ethyl acetate $(3 \times 1 \mathrm{~L})$ (Merck, New South Wales, Australia). The combined organic extract was dried over anhydrous $\mathrm{Na}_{2} \mathrm{SO}_{4}$ (Merck, New South Wales, Australia) and concentrated under reduced pressure to obtain ca. $0.3 \mathrm{~g}$ oily residue. This residue was then subjected to silica flash column chromatography, eluting with an increasing polarity of hexane (Merck, New South Wales, Australia) and ethyl acetate mixtures from 100\% hexane to $100 \%$ EtOAc. Flash column fractions $(37 \times 10 \mathrm{~mL}$ each) were collected and monitored by silica TLC under UV $(254 \mathrm{~nm})$ with vanillin and 2,4-dinitrophenyl-hydrazine (DNP) staining reagent applied to the air-dried TLC plates. Several fractions which were eluted with $\sim 70 \%$ hexane were subsequently combined and evaporated to provide a solid residue $(10 \mathrm{mg})$, which was confirmed by HRAM UPLC-MS/MS and ${ }^{1} \mathrm{H}$ and ${ }^{13} \mathrm{C}$ NMR (as described below) to contain a mixture of botrydial (1) and dihydrobotrydial (2).

\subsection{NMR Analysis of Botrydial and Dihydrobotrydial Standards}

The botrydial/dihydrobotrydial mixture $(10 \mathrm{mg})$ was analysed by ${ }^{1} \mathrm{H}$ and ${ }^{13} \mathrm{C}$ NMR in deuterated chloroform (Cambridge Isotope Laboratories, Inc.) on a $500 \mathrm{MHz}$ Bruker Avance instrument ( $5 \mathrm{~mm}$ Selective Excitation Inverse (SEI) probe) with addition of a measured aliquot of dioxane as internal standard for NMR quantification. Integration of aldehyde and dioxane ${ }^{1} \mathrm{H}$ NMR resonances was used to determine the amount of botrydial present in the sample. The sample containing botrydial $(0.8 \mathrm{mg})$ and dihydrobotrydial $(7.2 \mathrm{mg})$ was recovered from the NMR solvent $\left(\mathrm{CDCl}_{3}\right)$, and used without further purification as a mixed external standard in HRAM UPLC-MS/MS analysis as described below.

\subsection{Photosensitizer and Light Source}

A stock solution $(2000 \mu \mathrm{M})$ of natural curcumin was prepared by dissolving $73.8 \mathrm{mg}$ curcumin (Sigma Aldrich, St. Louis, MO, USA) in $50 \mathrm{~mL}$ propylene glycol (99.5\%, Sigma Aldrich, St Louis, MO, USA), which was then diluted 1:1 in sterile water $(50 \mathrm{~mL})$. Our preliminary study showed that this solution had no inhibition effect on the spores (data not shown). The curcumin stock solution was stored in a dark cool place, and diluted as 
appropriate with sterile water to provide required curcumin concentrations for photosensitizer experiments. The illumination source was a 500-Watt xenon arc lamp (Polilight, PL 500, Rofin Australia Pty Ltd., Victoria, Australia) equipped with an optical fibre light with a range of 370-680 nm filters. This source was configured according to the previously described method [22] and a wavelength of $430 \mathrm{~nm}$ was selected. The light dose $\left(\mathrm{J} / \mathrm{cm}^{2}\right)$ was calculated as irradiation time (s) multiplied by the light power $(\mathrm{w})$ divided by the area of irradiation $\left(\mathrm{cm}^{2}\right)$.

\subsection{Determination of Spore Survival under Differing Photosensitization Conditions}

A wide concentration range of curcumin $(50,100,200,400,600,800$, and $1000 \mu \mathrm{M})$ together with different levels of light doses $\left(0,120,240\right.$, and $360 \mathrm{~J} / \mathrm{cm}^{2}$, corresponding to an illumination time of $0,10,20$ and $30 \mathrm{~min}$, respectively) was utilized to determine an efficient photosensitization mediated curcumin treatment regime. Aliquots $(1 \mathrm{~mL})$ of both the fungal suspension and curcumin solution $(1: 1 v / v)$ were mixed in a Petri dish (30 $\mathrm{mm}$ diameter), and the light source was placed approximately $10 \mathrm{~cm}$ above the surface of the Petri dish. A magnetic stirrer bar was placed in the mixture $(2 \mathrm{~mL})$ to ensure constant stirring during illumination to expose all spores uniformly to the light energy. After illumination, aliquots $(100 \mu \mathrm{L})$ of the treated mixture were transferred onto Czapek Dox agar (3 replicates per treatment) and incubated with $12 \mathrm{~h}$ light/dark cycles at $26^{\circ} \mathrm{C}$ for 8 days to determine the colony forming units (CFU), with plates incubated under the same condition for a further 3 days for botrydial and dihydrobotrydial analysis. The percentage reduction in fungal spores after treatment was calculated by the number of the colony $(\mathrm{CFU})$ as given below, with the results of 3 replicates averaged for each treatment.

$$
\% \text { Reduction }=\left(\mathrm{CFU}_{\text {control }}-\mathrm{CFU}_{\text {test }}\right) / \mathrm{CFU}_{\text {control }} \times 100
$$

The selected optimized curcumin concentration and light dose were then utilized to investigate the effect of curcumin-mediated photosensitization on B. cinerea spores using treatment regimes of $\mathrm{D}^{+} \mathrm{L}^{+}$: curcumin $(800 \mu \mathrm{M})$ and light $\left(120 \mathrm{~J} / \mathrm{cm}^{2}\right) ; \mathrm{D}^{-} \mathrm{L}^{-}$(control): no curcumin and no light; $\mathrm{D}^{-} \mathrm{L}^{+}$: no curcumin and light $\left(120 \mathrm{~J} / \mathrm{cm}^{2}\right) ; \mathrm{D}^{+} \mathrm{L}^{-}$: curcumin $(800 \mu \mathrm{M})$ and no light followed by incubation at $26^{\circ} \mathrm{C}$ for $2-16$ days.

\subsection{Determination of Toxin Production under Differing Photosensitization Conditions}

B. cinerea-inoculated agar plates after photosensitization treatment and incubation (as described above) were also analysed by LC-MS/MS to determine botrydial and dihydrobotrydial production. A $1 \mathrm{~cm}$ diameter plug of agar, with an average weight of $0.25 \mathrm{~g}$, was selectively removed from the respective $B$. cinerea-inoculated agar plates and extracted with acetonitrile $(2.5 \mathrm{~mL})$ by sonication for $10 \mathrm{~min}$. The sonicated sample was then filtered ( $0.2 \mu \mathrm{m}$ polypropylene membrane syringe filter) and analysed by HRAM UPLC-MS/MS with results reported as $\mu \mathrm{g}$ botrydial or dihydrobotrydial per $\mathrm{g}$ of agar extracted. From each agar plate, three plugs were analysed as replicates.

Spiked recovery samples for metabolite analysis were prepared by addition of aliquots of the standard botrydial/dihydrobotrydial solution to $1 \mathrm{~cm}$ diameter plugs of agar from uninoculated agar plates at three different concentrations $(n=4)$, which were then extracted as above.

\subsection{HRAM UPLC-MS/MS Conditions}

UPLC separations were conducted out on an UltiMate 3000 RS UPLC system (Thermo Fisher Scientific, Bremen, Germany) equipped with an RS pump, a temperature control column compartment and an autosampler. An Agilent ZORBAX Eclipse Plus $C_{18}$ $(2.1 \mathrm{~mm} \times 100 \mathrm{~mm} ; 1.8 \mu \mathrm{m})$ column was used for the LC separations. The UPLC parameters consisted of column oven at $20{ }^{\circ} \mathrm{C}$, an injection volume of $2.0 \mu \mathrm{L}$, a flowrate of $0.2 \mathrm{~mL} / \mathrm{min}$ and gradient elution with mobile phase (MP) A: $0.1 \%$ formic acid in $\mathrm{H}_{2} \mathrm{O}$ and MP B: $0.1 \%$ formic acid in MeOH (MP B). The mobile phase gradient was $5 \% \mathrm{MP} B$ $(t=0)$ increasing to $40 \% \mathrm{MP} \mathrm{B}$ at $0.8 \mathrm{~min}, 80 \% \mathrm{MP}$ B at $1.5 \mathrm{~min}, 95 \% \mathrm{MP} \mathrm{B}$ at $2.2 \mathrm{~min}$ before 
reaching $100 \% \mathrm{MP} \mathrm{B}$ at $4 \mathrm{~min}$ and held there until $7 \mathrm{~min}$. MP B decreased to $5 \%$ at $7.3 \mathrm{~min}$ and was maintained at $5 \%$ until $10 \mathrm{~min}$.

The HRAM MS/MS was acquired on a Q-Exactive mass spectrometer (ThermoFisher Scientific, Bremen, Germany) with a heated electrospray ionization (HESI) probe. The MS data were collected in the parallel reaction monitoring (PRM) positive mode at 35,000 FWHM mass resolution, AGC target at 2.0e5, maximum IT at $100 \mathrm{~ms}$, mass isolation window of $4.0 \mathrm{~m} / \mathrm{z}$, Normalized Collision Energy (NCE) at 35 and an inclusion list containing botrydial $\left(\mathrm{C}_{17} \mathrm{H}_{27} \mathrm{O}_{5},[\mathrm{M}+\mathrm{H}]^{+} 311.1853\right)$ and dihydrobotrydial $\left(\mathrm{C}_{17} \mathrm{H}_{28} \mathrm{O}_{5} \mathrm{Na} ;[\mathrm{M}+\mathrm{Na}]^{+}\right.$ 335.1829). The source settings were set as follows: spray voltage at $3500(+)$, capillary temperature at $250{ }^{\circ} \mathrm{C}$, sheath gas at 45 (arbitrary units), Aux gas flow rate at 10, Aux gas heater temperature at $400^{\circ} \mathrm{C}$, S-lens RF level at 50 and Sweep gas flow rate at 2. A 5 ppm mass accuracy window was set for the mass extraction and detection setting. The HRAM UPLC-MS/MS system was controlled by Xcalibur ${ }^{\mathrm{TM}} 4.1$ software and the MS data were processed using TraceFinder ${ }^{\mathrm{TM}} 4.1$ software.

External standards in the range 1.02-9.92 $\mu \mathrm{g} / \mathrm{L}$ botrydial and 9.22-89.28 $\mu \mathrm{g} / \mathrm{L}$ dihdrobotrydial were used for quantification with PRM transitions for botrydial (1) of $\mathrm{m} / \mathrm{z}$ $311.1853 \rightarrow 205.1586$ for quantification (and $m / z 311.1853 \rightarrow 187.1481$ and $m / z 311.1853$ $\rightarrow 233.1534$ for confirmation) and for dihydrobotrydial (2) of $m / z 335.1829 \rightarrow 275.1614$ for quantification (and $m / z 335.1829 \rightarrow 217.1586$ for confirmation).

\subsection{Statistical Analyses}

All experiments were performed in triplicate. The value were expressed as mean $\pm \mathrm{SD}$. The analysis of statistical difference was performed using the TTEST function in Microsoft Excel 2010. Two-tails and 'type' for the test were choosen by the correspondence and variance of the data with FTEST. $p<0.05$ (significant), or $p<0.001$ (highly significant) were applied to determine any significant differences between specific means.

Supplementary Materials: The following are available online at https:/ / www.mdpi.com/2072-6 651/13/3/196/s1, Figure S1: Expansion of the botrydial MS/MS fragmentation spectra shown in Figure $2 \mathrm{~b}$ of the manuscript (A), together with further expansions of the spectra sections ranging from 80 to $150 \mathrm{~m} / z$ (B) and from 150 to $260 \mathrm{~m} / z$ (C), Figure S2: Effect of curcumin-mediated photosensitization on the inactivation of $B$. cinerea spores using increasing curcumin concentrations $(0-1000 \mu \mathrm{M})$ with a constant light dose of $120 \mathrm{~J} / \mathrm{cm}^{2}$; colonies of B. cinerea on Czapek Dox agar medium after incubation at $26^{\circ} \mathrm{C}$ for 8 days, Figure S3: Effect of photosensitization mediated curcumin on the inactivation of $B$. cinerea spore using different light dose $\left(0,120,240,360 \mathrm{~J} / \mathrm{cm}^{2}\right)$ under curcumin concentration of $800 \mu \mathrm{M}$; colonies of B. cinerea on Czapek Dox agar media after incubation at $26^{\circ} \mathrm{C}$, for 8 days, Figure S4: Effect of curcumin-mediated photosensitization on the inactivation of $B$. cinerea spore using different treatment regimes, after incubation at $26{ }^{\circ} \mathrm{C}$ for $2-$ 16 days; $\mathrm{D}^{-} \mathrm{L}^{-}$(control): no curcumin and no light; $\mathrm{D}^{-} \mathrm{L}^{+}$: no curcumin and light $\left(120 \mathrm{~J} / \mathrm{cm}^{2}\right) ; \mathrm{D}^{+} \mathrm{L}^{-}$: curcumin $(800 \mu \mathrm{M})$ and no light; $\mathrm{D}^{+} \mathrm{L}^{+}$: curcumin $(800 \mu \mathrm{M})$ and light $\left(120 \mathrm{~J} / \mathrm{cm}^{2}\right)$.

Author Contributions: Conceptualization, Y.S. and M.T.F.; data curation, L.H.; formal analysis, L.H., K.W.L.Y. and M.C.d.J.; investigation, L.H.; methodology, L.H., K.W.L.Y., W.C.F., M.C.d.J. and J.J.D.V.; resources, Y.S. and M.T.F.; supervision, Y.S. and M.T.F.; validation, K.W.L.Y.; writing-original draft, L.H.; writing-review and editing, L.H., K.W.L.Y., W.C.F., M.C.d.J., J.J.D.V., Y.S. and M.T.F. All authors have read and agreed to the published version of the manuscript.

Funding: This study was sponsored by Horticulture Innovation Australia Limited through the HN15001 Naturally Nutritious Project. Guangxi University Haina Project of Guangxi University provided funding for L.H. to undertake sabbatical study in Australia.

Institutional Review Board Statement: Not applicable.

Informed Consent Statement: Not applicable.

Data Availability Statement: Data available upon request.

Conflicts of Interest: The authors declare that there are no conflicts of interest. 


\section{References}

1. Food and Agriculture Organization Corporate Statistical Database. Food and Agriculture Data. Available online: http://www. fao.org/faostat/en/ (accessed on 14 November 2020).

2. Skrovankova, S.; Sumczynski, D.; Mlcek, J.; Jurikova, T.; Sochor, J. Bioactive compounds and antioxidant activity in different types of berries. Int. J. Mol. Sci. 2015, 16, 24673-24706. [CrossRef]

3. Dean, R.; Van Kan, J.A.L.; Pretorius, Z.A.; Hammond-Kosack, K.E.; Di Pietro, A.; Spanu, P.D.; Rudd, J.J.; Dickman, M.; Kahmann, R.; Ellis, J.; et al. The top 10 fungal pathogens in molecular plant pathology. Mol. Plant Pathol. 2012, 13, 414-430. [CrossRef]

4. Penha, C.B.; Bonin, E.; Da Silva, A.F.; Hioka, N.; Zanqueta, É.B.; Nakamura, T.U.; Filho, B.A.D.A.; Campanerut-Sá, P.A.Z.; Mikcha, J.M.G. Photodynamic inactivation of foodborne and food spoilage bacteria by curcumin. LWT 2017, 76, 198-202. [CrossRef]

5. Temba, B.A.; Fletcher, M.T.; Fox, G.P.; Harvey, J.; Okoth, S.A.; Sultanbawa, Y.; Temba, B. Curcumin-based photosensitization inactivates Aspergillus flavus and reduces aflatoxin B1 in maize kernels. Food Microbiol. 2019, 82, 82-88. [CrossRef]

6. Hu, J.; Lin, S.; Tan, B.K.; Hamzah, S.S.; Lin, Y.; Kong, Z.; Zhang, Y.; Zheng, B.; Zeng, S. Photodynamic inactivation of Burkholderia cepacia by curcumin in combination with EDTA. Food Res. Int. 2018, 111, 265-271. [CrossRef]

7. Foote, C.S. Mechanisms of photosensitized oxidation. There are several different types of photosensitized oxidation which may be important in biological systems. Science 1968, 162, 963-970. [CrossRef]

8. Abrahamse, H.; Hamblin, M.R. New photosensitizers for photodynamic therapy. Biochem. J. 2016, 473, 347-364. [CrossRef]

9. Sarwar, S.; Netzel, G.; Netzel, M.E.; Mereddy, R.; Phan, A.D.T.; Hong, H.T.; Cozzolino, D.; Sultanbawa, Y. Impact of curcuminmediated photosensitization on fungal growth, physicochemical properties and nutritional composition in Australian grown strawberry. Food Anal. Methods 2021, 14, 465-472. [CrossRef]

10. Choquer, M.; Fournier, E.; Kunz, C.; Levis, C.; Pradier, J.-M.; Simon, A.; Viaud, M. Botrytis cinerea virulence factors: New insights into a necrotrophic and polyphageous pathogen. FEMS Microbiol. Lett. 2007, 277, 1-10. [CrossRef]

11. Williamson, B.; Tudzynski, B.; Tudzynski, P.; Van Kan, J.A.L. Botrytis cinerea: The cause of grey mould disease. Mol. Plant Pathol. 2007, 8, 561-580. [CrossRef]

12. Fehlhaber, H.-W.; Geipel, R.; Mercker, H.-J.; Tschesche, R.; Welmar, K.; Schönbeck, F. Botrydial, ein sesquiterpen-antibiotikum aus der nährlösung des pilzes Botrytis cinerea. Eur. J. Inorg. Chem. 1974, 107, 1720-1730. [CrossRef]

13. Durán-Patrón, R.; Hernández-Galán, R.; Rebordinos, L.G.; Cantoral, J.M.; Collado, I.G. Structure-activity relationships of new phytotoxic metabolites with the botryane skeleton from Botrytis cinerea. Tetrahedron 1999, 55, 2389-2400. [CrossRef]

14. Dalmais, B.; Schumacher, J.; Moraga, J.; Le Pêcheur, P.; Tudzynski, B.; Collado, I.G.; Viaud, M. The Botrytis cinerea phytotoxin botcinic acid requires two polyketide synthases for production and has a redundant role in virulence with botrydial. Mol. Plant Pathol. 2011, 12, 564-579. [CrossRef]

15. Imada, K.; Tanaka, S.; Ibaraki, Y.; Yoshimura, K.; Ito, S. Antifungal effect of 405-nm light on Botrytis cinerea. Lett. Appl. Microbiol. 2014, 59, 670-676. [CrossRef] [PubMed]

16. Hanson, J.R.; Nyfeler, R. Biosynthesis of the sesquiterpenoids, botrydial and dihydrobotrydial. J. Chem. Soc. Chem. Commun. 1976, 10, 72-73. [CrossRef]

17. Collado, I.G.; Aleu, J.; Hernandez-Galan, R.; Duran-Patron, R. Botrytis Species: An intriguing source of metabolites with a wide range of biological activities. Structure, chemistry and bioactivity of metabolites isolated from Botrytis species. Curr. Org. Chem. 2000, 4, 1261-1286. [CrossRef]

18. Niedzwiecki, M.M.; Samant, P.; Walker, D.I.; Tran, V.; Jones, D.P.; Prausnitz, M.R.; Miller, G.W. Human suction blister fluid composition determined using high-resolution metabolomics. Anal. Chem. 2018, 90, 3786-3792. [CrossRef]

19. El Fellah, S.; Duporté, G.; Sirén, H. Steroid hormones, inorganic ions and botrydial in drinking water. Determination with capillary electrophoresis and liquid chromatography-orbitrap high resolution mass spectrometry. Microchem. J. 2017, 133, 126-136. [CrossRef]

20. Josewin, S.W.; Kim, M.-J.; Yuk, H.-G. Inactivation of Listeria monocytogenes and Salmonella spp. on cantaloupe rinds by blue light emitting diodes (LEDs). Food Microbiol. 2018, 76, 219-225. [CrossRef] [PubMed]

21. Temba, B.A.; Fletcher, M.T.; Fox, G.P.; Harvey, J.J.; Sultanbawa, Y. Inactivation of Aspergillus flavus spores by curcumin-mediated photosensitization. Food Control. 2016, 59, 708-713. [CrossRef]

22. Al-Asmari, F.; Mereddy, R.; Sultanbawa, Y. A novel photosensitization treatment for the inactivation of fungal spores and cells mediated by curcumin. J. Photochem. Photobiol. B Biol. 2017, 173, 301-306. [CrossRef]

23. Araújo, N.C.; De Menezes, R.F.; Carneiro, V.S.M.; Dos Santos-Neto, A.P.; Fontana, C.R.; Bagnato, V.S.; Harvey, C.M.; Gerbi, M.E.M. Photodynamic inactivation of cariogenic pathogens using curcumin as photosensitizer. Photomed. Laser Surg. 2017, 35, 259-263. [CrossRef]

24. Calzavara-Pinton, P.; Rossi, M.T.; Sala, R.; Venturini, M. Photodynamic antifungal chemotherapy. Photochem. Photobiol. 2012, 88, 512-522. [CrossRef] [PubMed]

25. Ahn, J.-C.; Kang, J.-W.; Shin, J.-I.; Chung, P.-S. Combination treatment with photodynamic therapy and curcumin induces mitochondria-dependent apoptosis in AMC-HN3 cells. Int. J. Oncol. 2012, 41, 2184-2190. [CrossRef] [PubMed]

26. Sanitá, P.V.; Pavarina, A.C.; Dovigo, L.N.; Ribeiro, A.P.D.; Andrade, M.C.; Mima, E.G.D.O. Curcumin-mediated anti-microbial photodynamic therapy against Candida dubliniensis biofilms. Lasers Med. Sci. 2018, 33, 709-717. [CrossRef] [PubMed]

27. Ghosh, S.; Banerjee, S.; Sil, P.C. The beneficial role of curcumin on inflammation, diabetes and neurodegenerative disease: A recent update. Food Chem. Toxicol. 2015, 83, 111-124. [CrossRef] 
28. Lin, C.-F.; Yu, K.-H.; Jheng, C.-P.; Chung, R.; Lee, C.-I. Curcumin reduces amyloid fibrillation of prion protein and decreases reactive oxidative stress. Pathogens 2013, 2, 506-519. [CrossRef]

29. Wikene, K.O.; Hegge, A.B.; Bruzell, E.; Tønnesen, H.H. Formulation and characterization of lyophilized curcumin solid dispersions for antimicrobial photodynamic therapy (aPDT): Studies on curcumin and curcuminoids LII. Drug Dev. Ind. Pharm. 2014, 41, 969-977. [CrossRef]

30. Da Frota, M.F.; Guerreiro-Tanomaru, J.M.; Tanomaru-Filho, M.; Bagnato, V.S.; Espir, C.G.; Berbert, F.L.C.V. Photodynamic therapy in root canals contaminated with Enterococcus faecalis using curcumin as photosensitizer. Lasers Med. Sci. 2015, 30, 1867-1872. [CrossRef]

31. Aggarwal, B.B.; Sundaram, C.; Malani, N.; Ichikawa, H. Curcumin: The Indian solid gold. Adv. Exp. Med. Biol. 2007, 595, 1-75. [CrossRef] [PubMed]

32. Moghadamtousi, S.Z.; Kadir, H.A.; Hassandarvish, P.; Tajik, H.; Abubakar, S.; Zandi, K. A review on antibacterial, antiviral, and antifungal activity of curcumin. BioMed Res. Int. 2014, 2014, 1-12. [CrossRef] [PubMed]

33. Dai, T.; Gupta, A.; Huang, Y.-Y.; Sherwood, M.E.; Murray, C.K.; Vrahas, M.S.; Kielian, T.; Hamblin, M.R. Blue light eliminates community-acquired methicillin-resistant Staphylococcus aureus in infected mouse skin abrasions. Photomed. Laser Surg. 2013, 31, 531-538. [CrossRef] [PubMed]

34. Zhang, Y.; Zhu, Y.; Gupta, A.; Huang, Y.; Murray, C.K.; Vrahas, M.S.; Sherwood, M.E.; Baer, D.G.; Hamblin, M.R.; Dai, T. Antimicrobial blue light therapy for multidrug-resistant Acinetobacter baumannii infection in a mouse burn model: Implications for prophylaxis and treatment of combat-related wound infections. J. Infect. Dis. 2013, 209, 1963-1971. [CrossRef]

35. Wang, C.; Yang, Z.; Peng, Y.; Guo, Y.; Yao, M.; Dong, J. Application of $460 \mathrm{~nm}$ visible light for the elimination of Candida albicans in vitro and in vivo. Mol. Med. Rep. 2018, 18, 2017-2026. [CrossRef]

36. Hamblin, M.R.; Hasan, T. Photodynamic therapy: A new antimicrobial approach to infectious disease? Photochem. Photobiol. Sci. 2004, 3, 436-450. [CrossRef]

37. Konopka, K.; Goslinski, T. Photodynamic therapy in dentistry. J. Dent. Res. 2007, 86, 694-707. [CrossRef] [PubMed]

38. Mengiste, T. Plant immunity to necrotrophs. Annu. Rev. Phytopathol. 2012, 50, 267-294. [CrossRef] [PubMed]

39. Van Baarlen, P.; Woltering, E.J.; Staats, M.; Van Kan, J.A.L. Histochemical and genetic analysis of host and non-host interactions of Arabidopsis with three Botrytis species: An important role for cell death control. Mol. Plant Pathol. 2007, 8, 41-54. [CrossRef]

40. Colmenares, A.J.; Aleu, J.; Durán-Patrón, R.; Collado, I.G.; Hernández-Galán, R. The putative role of botrydial and related metabolites in the infection mechanism of Botrytis cinerea. J. Chem. Ecol. 2002, 28, 997-1005. [CrossRef]

41. Rossi, F.R.; Gárriz, A.; Marina, M.; Romero, F.M.; Gonzalez, M.E.; Collado, I.G.; Pieckenstain, F.L. The sesquiterpene botrydial produced by Botrytis cinerea induces the hypersensitive response on plant tissues and its action is modulated by salicylic acid and jasmonic acid signaling. Mol. Plant Microbe Interact. 2011, 24, 888-896. [CrossRef]

42. Durán-Patrón, R.; Cantoral, J.M.; Hernández-Galán, R.; Hanson, J.R.; Collado, I.G. The biodegradation of the phytotoxic metabolite botrydial by its parent organism, Botrytis cinerea. J. Chem. Res. 2004, 2004, 441-443. [CrossRef]

43. Liñeiro, E.; Macias-Sánchez, A.J.; Espinazo, M.; Cantoral, J.M.; Moraga, J.; Collado, I.G.; Fernández-Acero, F.J. Phenotypic effects and inhibition of botrydial biosynthesis induced by different plant-based elicitors in Botrytis cinerea. Curr. Microbiol. 2017, 75, 431-440. [CrossRef] [PubMed]

44. De Oliveira, E.F.; Tosati, J.V.; Tikekar, R.V.; Monteiro, A.R.; Nitin, N. Antimicrobial activity of curcumin in combination with light against Escherichia coli O157:H7 and Listeria innocua: Applications for fresh produce sanitation. Postharvest Biol. Technol. 2018, 137, 86-94. [CrossRef]

45. Tao, R.; Zhang, F.; Tang, Q.-J.; Xu, C.-S.; Ni, Z.-J.; Meng, X.-H. Effects of curcumin-based photodynamic treatment on the storage quality of fresh-cut apples. Food Chem. 2019, 274, 415-421. [CrossRef] [PubMed]

46. Kidd, S.; Halliday, C.; Alexiou, H.; Ellis, D. Descriptions of Medical Fungi; Newstyle Printing: Adelaide, Australia, 2016; Available online: https:/ / mycology.adelaide.edu.au/docs/fungus3-book.pdf (accessed on 14 November 2020).

47. White, T.J.; Bruns, T.; Lee, S.; Taylor, J. Amplification and direct sequencing of fungal ribosomal RNA genes for phylogenetics. In PCR Protocols: A Guide to Methods and Applications; Innis, M., Gelfand, D., Shinsky, J., White, T., Eds.; Academic Press: New York, NY, USA, 1990; pp. 315-322. 